\title{
Diego García Conde, un militar español en la transición al México Independiente
}

\author{
por \\ José Omar Moncada Maya e Irma Escamilla Herrera \\ Universidad Nacional Autónoma de México \\ moncadamaya@yahoo.com.mx \\ ieh@igg.unam.mx
}

Diego García Conde perteneció a una importante saga familiar de militares españoles del siglo XVIII que alcanzaron posiciones relevantes en la estructura del Ejército. Los cuatro hermanos García Conde alcanzaron el rango de Mariscal de Campo, dos de ellos desarrollaron su actividad en España, mientras que los otros dos fueron destinados a la Nueva España. Diego García Conde destacó en forma particular, toda vez que sirvió tanto al gobierno colonial español como al nuevo Estado independiente mexicano, en funciones de Comandante militar y Gobernador Intendente. Fue el primer Director de Ingenieros de la nueva nación, así como Director de la Academia de Cadetes. Pero, además, como ingeniero voluntario, desarrolló una importante labor técnico-científica. Destaca el mapa que elaboró de la ciudad de México.

Palabras clave: Diego García Conde; ingeniero militar; Nueva España; Cartografía.

\section{INTRODUCCIÓN}

Los García Conde fueron una importante familia de militares españoles, algunos de cuyos miembros se trasladaron a la Nueva España durante la segunda mitad del siglo XVIII, y cuya presencia en México se extiende por más de un siglo, habiendo figurado de manera destacada en la vida política, tanto bajo el régimen virreinal como ya entrado el periodo independiente. Emprendemos aquí el estudio de uno de los miembros de esta saga familiar: Diego García Conde, militar, ingeniero, funcionario, personaje multifacético 
que en cierto modo representa a los personajes de la Ilustración española de la segunda mitad del siglo XVIII trasladados a tierras americanas.

En 1908 se publicó la obra de Ricardo Ortega y Pérez Gallardo, Historia genealógica de las familias más antiguas de México, donde considera a la familia García Conde ${ }^{1}$. De ella se obtuvieron datos que nos permiten establecer como punto de partida el matrimonio de Alejo García Conde, natural de Navarra, y quien llegó a alcanzar los grados de teniente coronel de infantería y sargento mayor de la plaza de Barcelona, con Teresa García Conde ${ }^{2}$, su prima, natural de Ceuta. De esta unión se tiene noticia del nacimiento de cinco varones, de los que cuatro siguieron la carrera de las armas: Alejo, Diego, Antonio y Juan, mientras que Jaime, probablemente el segundo de los hermanos, fue presbítero y murió siendo Deán de la catedral de Tortosa ${ }^{3}$. Mientras que los dos últimos realizaron toda su carrera militar en la Metrópoli, los dos primeros fueron destinados a la Nueva España ${ }^{4}$.

De Antonio García Conde disponemos de muy poca información: ingresó en 1775 como cadete al Regimiento de Reales Guardias Españolas. Siendo capitán, en 1796 se encuentra entre los oficiales que rinden la plaza de San Fernando de Figueras, por lo que sufre prisión en Portugal; a su regreso a España, el Consejo de Guerra de Oficiales Generales formado en Barcelona en ese mismo año, lo juzga y le impone un año de arresto. Pese a ello, continuará su trayectoria y alcanzará los grados de Brigadier en 1802, Mariscal de Campo en 1810 y Teniente General en 1825. Recibió la Gran Cruz de la Real y Militar Orden de San Hermenegildo ${ }^{5}$.

${ }^{1}$ Ortega y Pérez Gallardo, 1908, vol. III: 5. Vale aclarar que esta obra inicia su paginación en cada una de las familias que trata, por tanto, el número indica la página respecto a la Familia García Conde, que se localiza en el tercer y último volumen de la obra.

${ }^{2}$ Hoja de Servicio de Alejo García Conde, Archivo General Militar de Segovia, Segovia, España (AGMS), 776.

${ }^{3}$ Idem.

${ }^{4}$ Es necesario corregir la información que da Ortega y Pérez Gallardo, toda vez que establece que los hermanos son, de mayor a menor, Juan, Antonio, Jaime, Alejo y Diego. Sin embargo, las fechas que tenemos de sus nacimiento señalan: Alejo, 1751, Diego, 1760 y Juan, 1768. Si todos ellos entraron como cadetes a la edad de 12 a 13 años, Antonio debió haber nacido hacia 1762-1763. Entonces, es probable que Jaime fuera el segundo hermano.

${ }^{5}$ La información sobre Antonio García Conde se encontró de forma dispersa en los siguientes periódicos: Mercurio Histórico y Político, Madrid, mayo de 1782, tomo II: 166 (periódico mensual). Mercurio de España, Madrid, enero de 1799, tomo I: 111-113 (Mercurio de España es el nombre adoptado por el Mercurio Histórico y Político a partir de 1784); Guía de Forasteros (Madrid), 1807: 18. Kalendario manual y Guía de Forasteros en Madrid, Madrid, 1810: 15 y 72; Guía Patriótica de España para el año de 1811, Real Isla de León, 1811: 135; Guía de Forasteros (Madrid), 1821: 15. Todos los periódicos están para consulta en la Biblioteca Nacional de Madrid. 
Juan García Conde, el menor de los hermanos, nació en 1768, natural de Barcelona. En 1781 ingresó como cadete, al igual que sus hermanos en el regimiento de Reales Guardias Españolas y, pasando por todos los empleos de escala, en 1815 alcanzó el rango de Mariscal de Campo. Durante la Guerra de Independencia fue hecho prisionero y trasladado a Francia; a su regreso a España «fue purificado de su conducta durante el tiempo que se vio privado de su libertad y rehabilitado en el ejercicio de su empleo». En 1810 se le promovió a Comandante del $4^{\circ}$ Batallón de Reales Guardias Españolas, residente en Madrid. En 1826 se le nombró Comandante General de la provincia de la Mancha, cargo que ocupó hasta su muerte. Por su participación en la Guerra de Independencia fue nombrado Benemérito de la Patria en grado heroico; también se le nombró Caballero Gran Cruz de la Real y Militar Orden de San Hermenegildo. De sus pocos datos personales, sabemos que contrajo matrimonio con Luisa Attelis Vender, hija del marqués de Santo Angelo. Falleció el 7 de septiembre de 1832, en Ciudad Real ${ }^{6}$.

\section{Los García Conde en AmÉrica}

Los dos hermanos García Conde que fueron destinados al Nuevo Mundo lo hicieron en condiciones muy diferentes, pero en cualquier caso, pese a tener la oportunidad de regresar a la península, no tenemos noticia de que en algún momento lo hayan solicitado; ello confirmaría la idea de Alonso Baquer de que los ingenieros y militares descubrieron más posibilidades para su vocación científica, política y militar en los territorios de ultramar que en la propia metrópoli ${ }^{7}$.

Cuando los hermanos García Conde son destinados a Nueva España, las condiciones del ejército habían mejorado sustancialmente. Las reformas emprendidas por la nueva dinastía de los Borbones se reflejaban en todos los niveles de los territorios bajo soberanía española, y los diferentes cuerpos del ejército no fueron la excepción. Así, en 1764 se envía al teniente general Juan de Villalba y Angulo para que reorganice el ejército, al mando de 963 oficiales y tropa, que constituyeron la base del nuevo ejército novohispano. Como parte de la expedición se incluyó una brigada de siete ingenieros, que permitieron consolidar a la Dirección de Ingenieros de la Nueva España como la más importante y numerosa en América.

\footnotetext{
${ }^{6}$ Hoja de Servicio..., AGMS, 776. "Necrología (Juan García Conde)”, Gaceta de Madrid, Año de 1832, Madrid, Imprenta Real, 1832: 534.

7 Alonso Baquer, 1972: 38.
} 
Alejo García Conde nació el 2 de agosto de 1751 en Ceuta $^{8}$, donde el padre se encontraba destinado. En Barcelona inició su carrera militar, en junio de 1763, como cadete de Reales Guardias de Infantería Española, ascendió a alférez en junio $1775^{9}$. Estuvo presente en la campaña de Argel y en el sitio de Gibraltar, en donde permaneció cuatro años, siendo voluntario en «la flotante San Cristóbal, mandando un piquete de su regimiento». Los ascensos alcanzados se dieron en los siguientes años: alférez de granaderos, 1777; segundo teniente de fusileros, 1779; segundo teniente de granaderos, 1782; teniente coronel, 1783.

En 1784 se le nombró Gobernador de la provincia de Comayahua, en la actual Honduras; al año siguiente se le nombra primer teniente de fusileros, y en 1792 asciende a coronel. En 1796 se le promovió como Gobernador Intendente de la provincia de Sonora y Sinaloa, de la Nueva España, con sede en Arizpe, Sonora, en sustitución de Enrique de Grimarest, quien había formado parte del cuerpo de ingenieros ${ }^{10}$. En este cargo hizo numerosas campañas contra los seris y los apaches; en su hoja de servicios señala que hasta 1812 había lanzado 78 campañas contra los indios, que daban por resultado 388 prisioneros y 199 muertos, sin contar las pequeñas acciones que requerían las urgencias, destacando la realizada en 1795 en contra de los primeros. En esa ocasión, al mando de 500 soldados, cuatro buques y tres canoas los atacó en la isla de Tiburón, diezmándolos de manera importante ${ }^{11}$. El 2 de octubre de 1802 alcanzó el grado de Brigadier.

Al estallar el movimiento de independencia combatió del lado del Rey; entre sus hechos de armas más destacados logró expulsar el movimiento de su provincia, llegando a enviar auxilio a las provincias de Nueva Vizcaya y Nueva Galicia. Ello le valió su ascenso a Mariscal de Campo en 1811. Posteriormente, en 1817 , se le nombró Gobernador Intendente de la Nueva Vizcaya, una de las más grandes del virreinato pues cubría los actuales estados de Durango y Chihuahua y el sur del Nuevo México, era habitada por numerosos grupos indígenas que hacían difícil el desarrollo de las actividades de los colonos hispanos, dedicados en su gran mayoría a la minería y a la ganadería. En noviembre de ese mismo año tomó el mando de las Provincias Internas de Occidente. Entre sus múltiples disposiciones como gobernante destaca la prohibición terminante de que se aplicara la pena de azotes a los indios, por considerarlo inhumano.

\footnotetext{
${ }^{8}$ Ortega y Pérez Gallardo, 1908, vol. III: 5. A esta obra pertenecen la mayor parte de los datos de su trayectoria militar que aquí se presentan.

9 Idem. Almada, 1952: 294.

${ }_{10}$ Moncada Maya, 1993: 112-113.

11 Ortega y Pérez Gallardo, 1908, vol. III: 28.
} 
El 24 de agosto de 1821 secundó en Chihuahua el Plan de Iguala, disponiendo que fuera jurado por todos los pueblos de la provincia a su mando; así quedó integrado dentro de la nueva república y le fue reconocido el grado de General de División. Para 1822 ya se encontraba residiendo en la ciudad de México. Entre los reconocimientos que alcanzó se cuentan las condecoraciones de las órdenes de San Fernando y San Hermenegildo, que le otorgó el rey Fernando VII, así como Caballero de la Orden de Guadalupe. Murió en la ciudad de México el 28 de julio de 1826, y fue sepultado en la iglesia de la Santa Veracruz, más tarde se trasladaron sus restos a la iglesia de Los Ángeles ${ }^{12}$.

La única información que poseemos sobre su vida personal es el haber contraído matrimonio, en primeras nupcias, con Tomasa María del Carmen Juana Nepomucena Sastre y Conde, natural de Galicia. De esta unión nacieron María del Carmen y Alejo, quien murió a los 18 años, en Guatemala. Posteriormente, ya en Nueva España, casó con Ma. Teresa de Jesús Juana Nepomucena Vidal de Lorca, originaria de la Hacienda de Galán, Real de Charcas, en el actual estado de San Luis Potosí13. De este matrimonio nacieron diez hijos. De los cinco varones, cuatro siguieron la carrera de las armas: Alejo, Rafael, quién se retiró del ejército por haber perdido una pierna, Francisco y Pedro. Joaquín, el menor de todos, llegó a ser cónsul general de México en San Francisco, Burdeos, El Havre y en Liverpool ${ }^{14}$.

Brevemente señalamos la trayectoria militar que siguieron los hijos de Alejo: el que lleva su mismo nombre llegó a comandante general de Durango; Francisco fue diputado, senador, comandante general en Oaxaca, Coahuila y Chihuahua, cuartel maestre del Ejército del Norte y, por un breve tiempo, gobernador de la ciudad de México. Alcanzó el grado de general en 1840. Finalmente, Pedro, el más destacado de ellos, obtuvo el título de ensayador de minas en el Colegio de Minería y en su carrera militar también alcanzó el grado de general, fue profesor fundador del arma de Ingenieros, Director del Colegio Militar, ministro de Guerra, diputado, senador y comisionado mexicanos para el trazo de la frontera entre México y los Estados Unidos de América. De su obra cartográfica destacan el «Plano topográfico del Distrito Federal», la «Carta geográfica de Chihuahua»y, sobre todo, la «Carta geográfica general de la República Mexicana»» ${ }^{15}$.

\footnotetext{
${ }^{12}$ Idem, da como año de su muerte el de 1827.

13 Idem.

14 Idem.

${ }^{15}$ Moncada Maya, 2004: 173-214.
} 


\section{Diego García Conde}

La primera noticia publicada que tenemos de él se debe a un contemporáneo suyo, que por este sólo hecho ya es digno de tomar en consideración el prestigio de que debía gozar. José Mariano Beristáin de Souza lo incluyó en su magna Bibliotheca Mexicana, cuya primera edición, de 1816, dice de nuestro personaje:

Natural del principado de Cataluña. De Alférez de Reales Guardias Españolas pasó de Capitán al Regimiento de Dragones de México, de cuyo grado ascendió por su antigüedad y sobresalientes méritos al de Brigadier con el mando del Regimiento Provincial de Dragones de Puebla. En la revolución general de la N. E. acreditó su valor, pericia militar, y política; y hoy se halla de Comandante General de las armas de la Provincia de Zacatecas. De su buen gusto e inteligencia en la música y poesía ha dado bastantes pruebas en varias Canciones, que ha compuesto en elogio de los Jefes y Tropas Hispano Americanas y para fomentar su entusiasmo patriótico. Y de sus vastos conocimientos y aplicación en las Matemáticas, especialmente en la Arquitectura y Geografía serán eternos monumentos el nuevo camino de Veracruz a Jalapa, el famoso Puente del Rey sobre el Río de la Antigua, y el hermoso, magnífico y exactísimo Plan ó Mapa Topográfico de la Ciudad de Mégico, que publicó en 18... escribió también: Noticia circunstanciada de los trabajos y necesidades, que en compañia del Coronel Rul y del Intendente Merino heridos y golpeados, pasó el Autor prisionero de los Insurgentes y del manejo y proyectos de estos enemigos. Ms. ${ }^{16}$.

Diego, nueve años menor que Alejo, nació en la ciudad de Barcelona en julio de 1760, fue bautizado en la catedral de la ciudad condal el día 27 de dicho mes con el nombre de Diego Santana Joaquín ${ }^{17}$. Ingresó como cadete en las Reales Guardias Españolas el 31 de julio de 1772, cuando apenas cumplía los doce años, sin duda por la influencia de la familia pues su hermano había formado parte de dicho regimiento. Un año después, el 27 de marzo de 1773, ascendía a alférez, en el mismo cuerpo ${ }^{18}$.

Durante esta etapa de su formación militar existe un gran hueco de información, y sólo sabemos por su hoja de servicios que «se halló en el Bloqueo y Sitio de Gibraltar en la Guerra del año de $1780 \gg{ }^{19}$. Después de ello volvemos a tener noticias de él hasta 1787, cuando el 27 de diciembre se le asciende

16 Beristáin de Souza, 1883, vol. II: 24. (La edición original es de 1816-1821).

17 Hoja de Servicio..., AGMS, 776. Para facilitar la lectura, se actualizó la ortografía en la transcripción de textos con excepción de los títulos de los mapas, extendiéndose las abreviaturas, pero respetando la puntuación.

${ }_{18}^{18}$ Idem.

${ }^{19}$ Idem. 
a segundo teniente en el mismo regimiento. Pocos meses después se da un hecho que cambiará el rumbo de su vida: el 27 de abril de 1788, estando de parada en el Real sitio de Aranjuez, tiene un desafío con el alférez de Reales Guardias Walonas Enrique de Saint Hilaire, razón por la cual es arrestado y enviado a Peñíscola. Ahí se le mantuvo preso hasta principios de 1789, cuando el rey Carlos IV, en su exaltación al trono, lo indulta y dispone pase a servir a la Nueva España ${ }^{20}$. De manera que el 2 de febrero de 1789 se encuentra como capitán agregado al Regimiento de Dragones de México. Y al año siguiente, el 2 de enero se le designa capitán efectivo ${ }^{21}$.

Pese a que la Dirección de Ingenieros de la Nueva España era la más numerosa e importante de ultramar, estaba lejos de satisfacer las necesidades del reino, razón por la que, desde la península, se aceptó la figura de los «ingenieros voluntarios». De acuerdo con la Ordenanza del Real Cuerpo de Ingenieros expedida en 1768, para ser ingeniero voluntario era necesario haber cursado con aprovechamiento las matemáticas, y su función principal debía ser suplir la falta de ingenieros en las expediciones; sin embargo, sus actividades fueron más allá, pues participaron en el diseño y construcción de importantes obras públicas siendo reconocidos como notables ingenieros ${ }^{22}$. Así, Diego solicita y se le acepta como ingeniero voluntario, ejerciendo desde 1790 hasta $1810^{23}$.

De hecho, la primera referencia a su actividad técnico científica se da de manera inmediata a su incorporación, pues en 1791 participa en un reconocimiento del camino de la sierra de Meztitlán ${ }^{24}$, actual estado de Hidalgo, actividad en la que, puede decirse, se especializará. En 1792 informa que levantó el plano de pueblo de Tulancingo, que entregó al virrey y una copia al subdelegado ${ }^{25}$.

En ese mismo año, el virrey segundo conde de Revillagigedo le nombra para levantar el mapa de la ciudad capital, cuyo costo de los grabados, láminas e impresiones sería con cargo a la ciudad. De dicha actividad se obtuvo uno de los mapas más representativos de la ciudad de México, y que a su autor le valió gran reconocimiento. Desgraciadamente, tuvieron que pasar catorce años para que dicho plano, grabado por el profesor Joaquín Fabregat, cate-

\footnotetext{
${ }^{20}$ Navarro García y Antolín Espino, 1972: 579.

21 Hoja de Servicio..., AGMS, 776.

22 Moncada Maya, 1994: 84.

23 Archivo Histórico de la Secretaría de la Defensa Nacional, México DF (AHSDN), Dirección de Archivo e Historia, I-28: 1-2.

24 Archivo General de la Nación, México DF (AGNM), Caminos y Calzadas, vol. 4, fol. 131-137; vol. 13, exp. 8, fol. 146-182; exp. 16, fol. 268-325.

25 AGNM, Archivo Histórico de Hacienda, caja 347, exp. 42.
} 
drático de la Academia de San Carlos, pudiera imprimirse. Se trata del Plano General de la Ciudad de México, levantado por el Teniente de Dragones Don Diego García Conde, en el año de 1793, y grabado en el de 1807, de orden de la misma Nobilísima Ciudad ${ }^{26}$, y que trataremos más adelante. No deja de sorprender designación misma de García Conde, ni la calidad del trabajo alcanzado por él, toda vez que no existen antecedentes de que hubiera realizado algún trabajo semejante, ni en España ni en el virreinato.

Sobre Diego García Conde existe un buen número de expedientes en el Archivo General de la Nación de México. Algunos de ellos, los más voluminosos, se refieren a su participación en obras públicas, particularmente la construcción del camino México a Toluca, obra en la que intervino entre 1793 y 1796, como primer ayudante del ingeniero Manuel Agustín Mascaró; en esta comisión tuvo la oportunidad de trabajar con Bernardo de Bonavia, intendente de México, y el destacado arquitecto valenciano Manuel Tolsá.

De acuerdo con León García:

La población hispana de Toluca era la más influyente y rica, dedicada a la producción, procesamiento y comercialización de alimentos para la ciudad de México y otras ciudades menores y pueblos como Valladolid, Puebla y Zacatecas, Celaya y Pungarabato. El valle de Toluca era el punto intermedio y vía de acceso entre el valle central de México, el norte y el occidente. Para la segunda mitad del siglo XVIII, el proyecto para la construcción del camino carretero de México a Toluca, se justificaba con la posibilidad de abaratar costos y disminuir el tiempo en el transporte de los alimentos que se producían no sólo en el valle de Toluca, sino también los de Cuernavaca y los de la zona de Michoacán y Guadalajara para abastecer a la capital ${ }^{27}$.

A finales de 1796 se hace pública la declaración de guerra de España en contra de la Gran Bretaña y, ante la posibilidad de un ataque inglés a Veracruz, se estableció un cantón militar en la villa de Orizaba. En enero de 1797 el virrey Branciforte nombra al coronel e ingeniero en jefe Miguel Constanzó como cuartel maestre general del ejército e intendente general del acantonamiento, quien a su vez designó a Diego García Conde como su ayudante ${ }^{28}$, asignándoles como una de sus primeras funciones el «...disponer la compostu-

${ }^{26}$ Instrucciones y Memorias..., 1991, vol. 2: 1.394.

${ }^{27}$ León García, 2002.

${ }^{28}$ AGNM, Correspondencia virreyes, vol. 187, fol. 57. Cuando fue nombrado «ayudante del cuartel Maestre del ejército de acantonamiento», en 24 de febrero de 1797, se le indicaba como el «único oficial de los cuerpos de este Ejercito instruido en las materias y capaz de desempeñar el encargo»; en esta comunicación queda manifiesta la carencia en que se hallaban Nueva España y Filipinas de ingenieros. 
ra de caminos por donde había de dirigirse la marcha de las tropas» ${ }^{29}$, es decir de la ciudad de México a la villa de Orizaba. Posteriormente se comunicó a Constanzó que debía continuar la compostura del camino hasta el puerto de Veracruz, para facilitar el tránsito de carruajes y artillería. Sin embargo, el aspecto más importante de las actividades de estos militares en el tiempo que duró el acantonamiento fue elaborar un Reconocimiento geográfico con fines estratégicos de la zona comprendida entre las costas de Veracruz y la ciudad de Orizaba ${ }^{30}$. En términos generales, el reconocimiento consistió en viajar por los tres caminos que, cruzando la Sierra Madre Oriental, podría seguir un ejército enemigo hacia la ciudad de México: la cuesta de Aguatlán, la cuesta de Maltrata y la cuesta de Aculcingo, estableciendo las dificultades y ventajas que ofrecían los caminos para el transporte de hombres y materiales de guerra.

El reconocimiento, aparte de los aspectos puramente militares, ofrece una importante información sobre los más variados temas de interés regional, como podían ser: el comercio de la nieve del Pico de Orizaba al puerto de Veracruz ${ }^{31}$, las condiciones ambientales de las zonas costeras tropicales, el acaparamiento de las tierras y su consecuente despoblamiento, las condiciones de vida de la población, particularmente los mulatos, y otros más. Acompañaba al reconocimiento un Mapa general de los terrenos que se comprenden entre el rio de la Antigua y la Barra de Alvarado, hasta la Sierra de Orizaba y Xalapa, levantado de orden del Excelentísimo Señor Virey Marqués de Branciforte (figura 1), firmado por Constanzó y por García Conde ${ }^{32}$.

Posterior a su participación en este reconocimiento se sucedieron varios hechos de importancia, tanto en el ámbito personal como profesional. En primer término, se le concede licencia real para contraer matrimonio; en agosto de 1800 se le asciende a sargento mayor y dos años después es teniente coronel graduado, para en 1804 alcanzar el grado de teniente coronel efectivo ${ }^{33}$.

29 AGNM, Indiferente de Guerra, vol. 158, fol. 2.

30 Archivo Histórico del Instituto Nacional de Antropología e Historia, México DF (AHINAH), Sección de Manuscritos, 2a serie, leg. 43-1. Moncada Maya, 1992: 31-64.

31 Idem. Este aspecto lo conoció directamente García Conde, que obtuvo información acerca de su «saca y conducción» a Veracruz, adonde enviaban nueve cargas diarias, a un costo de un peso el corte y tres de flete o conducción. Cada operario, originarios todos ellos de San Juan Coscomatepec, llegaba a cortar de cinco a siete cargas diarias, pero no llegaban a permanecer más de cinco días en la montaña, turnándose por semanas.

32 Localizado en el Museo Naval, Madrid, IX-A-14.

33 Ya con anterioridad había solicitado este ascenso, que le fue rechazado en 1799: «El Rey no ha venido en conceder a don Diego García Conde, capitán del Regimiento de Dragones de México, el grado de teniente coronel que solicita en la instancia que me remitió al antecesor de V. E., en carta N. 1082 de 30 de mayo último. Lo aviso a V. E. de Real orden 
Figura 1. Mapa general de los terrenos Que Se COMPRENDEN ENTRE EL río de la Antigua y la Barra de Alvarado, hasta la Sierra de Orizaba y Xalapa, elaborado por Miguel Constanzó y Diego García Conde, 1797

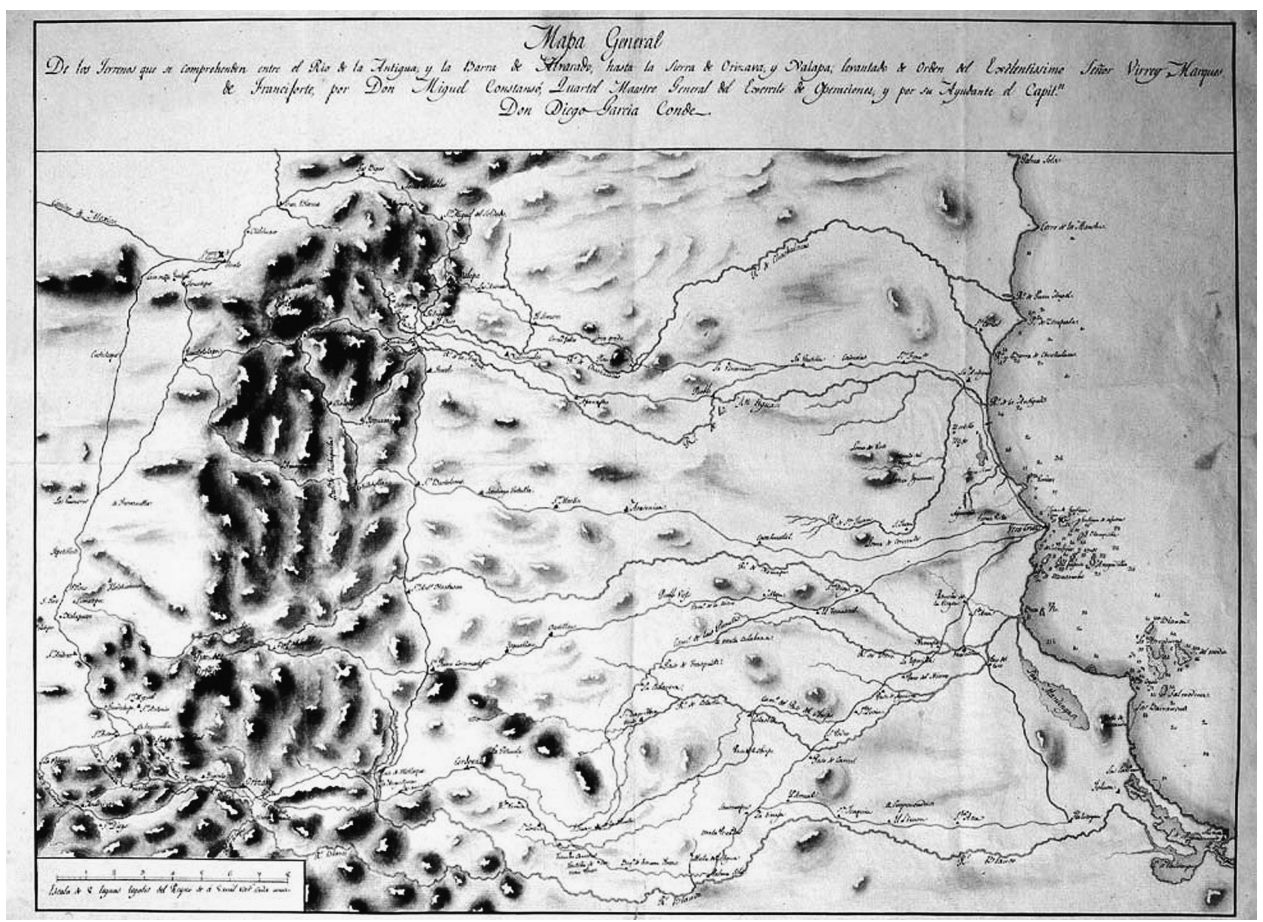

Fuente: Museo Naval, Madrid, IX-A-14.

Una última obra en la que intervino Diego García Conde a la que es necesario hacer referencia es la construcción del Puente del Rey. El camino más importante del virreinato era sin duda el de Veracruz a México por Jalapa, que junto con su ruta competidora por Orizaba recibió la mayor atención de las autoridades; sin embargo, sería durante las dos últimas décadas del siglo cuando se trató de dar solución al mayor problema en su recorrido: la construcción de un puente sobre el río de La Antigua. Diego Panes (figura 2), también ingeniero voluntario reconocía que

para su inteligencia y noticia del interesado...», AGNM, Reales Cédulas Originales, vol. 171, exp. 102, firmada en San Lorenzo el 15 de mayo de 1798. 


\section{Figura 2. Primer proyecto de García Conde del puente sobre el río De la Antigua, 1799}

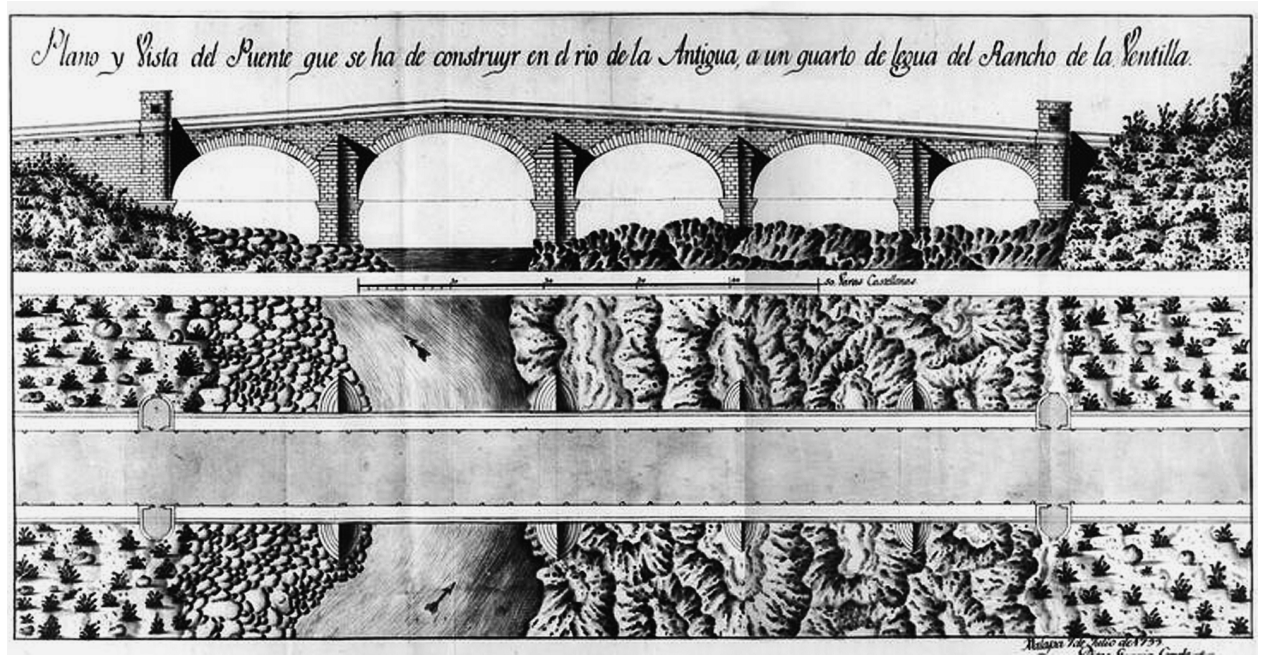

Fuente: Archivo General de la Nación, México DF, Fomento Caminos, vol. 6, $1^{\mathrm{a}}$ parte, fasc. 221 bis, 979/0085.

El paso del Río de La Antigua siempre penoso, siempre arriesgado, y difícil de asegurar ha costado mucho caudal, muchas vidas, y continuas averías: con variedad de proyectos se ha pretendido conseguir el pronto, y fácil tránsito de este río tan preciso para el comercio del reino por el rumbo de Xalapa, y jamás se ha logrado ${ }^{34}$.

En 1798 el virrey Azanza comisiona a García Conde para hacer un reconocimiento del camino de México a Veracruz, por la ruta de Xalapa, del cual se entrega un completo informe. Más que los asuntos técnicos, nos referimos aquí a sus preocupaciones respecto al papel que podía jugar la población local en la conservación del camino:

... Por esta causa, debe inferirse cuan útiles serían las poblaciones inmediatas al camino a su conservación, pues de lo contrario era menester a cada paso traer la gente de pueblos muy distantes con grave perjuicio de todos y aun de la obra. Yo no tengo por difícil ver conseguido este intento sin más que señalar los sitios oportunos como son: El Manantial entre Veracruz, y el Río de la Antigua: la Rinconada o sus inmediaciones en donde se halle agua con más proximidad, y otro también que puede situarse, o en el En cero (sic por El Encero), o bien en Corral falso. Ya estando señalados los parajes, y cediendo a cada individuo que quiera

\footnotetext{
${ }^{34}$ AGNM, Fomento Caminos, vol. 5, exp. 1, fol. 16.
} 
establecerse en ellos el terreno suficiente para jacal, corral, y alguna cosa más para los árboles frutales, u hortaliza que quisiesen tener, se prohibiría que ninguno pueda establecerse en los tramos intermedios del camino para que no vivan desparramados y a su libertad; y al contrario así se hallen congregadas treinta familias en cualesquiera de los parajes expresados, podrán formar pueblo señalándoles el terreno que ordenan las leyes, junto con el cura párroco y justicia. De este modo pienso que lograríamos atraer muchas gentes con utilidad del Estado, y de la Iglesia, que en el día de hoy ya hostigados de los propietarios de las tierras que no pueden sufrir a nadie en sus dominios por tenerlas totalmente entregadas al ganado, o bien por huir a buscar su libertad viven extraviados en los montes sin ley, ni rey, y más como gentiles que como cristianos.

A este proyecto y justa providencia no preveo puedan oponerse con razón y justicia los actuales poseedores fundándome en que cuando se les concedió las gracias, o las mercedes (que así se llaman) por los Señores Virreyes o Superior Gobierno fue siempre reservándose el rey su derecho para cederlo a pueblos o villas de españoles que se fundase, insertando siempre en las mismas gracias estas expresiones para que en ningún tiempo pudiesen alegar contra ellas ${ }^{35}$.

Así, pese a todos estos esfuerzos realizados por los ingenieros militares, no se realizaron obras significativas; las autoridades se limitaron a hacer mejoras al viejo camino. Por ello, a principios del siglo XIX el puente sobre el río de la Antigua seguía sin construirse, hasta que, finalmente, en abril de 1803 se nombra de nueva cuenta a Diego García Conde para dirigir la obra del camino de Veracruz a Xalapa.

Humboldt recorrió ese mismo camino a su salida del reino, antes de la construcción del puente, y escribió:

Sería útil construir un puente en el río de La Antigua, cerca de la Ventilla, en donde el albeo sólo tiene 107 metros de ancho, entonces el camino de Jalapa sería más de seis leguas más corto, y sin tocar la antigua Veracruz... y si se acortase una parte del camino que atraviesa estas áridas llanuras de la costa, se disminuirían los destrozos de esta pestilente enfermedad (la fiebre amarilla) ${ }^{36}$.

Las obras debieron iniciarse hacia 1805; sin embargo, la fuerte temporada de lluvias de 1806 afectó seriamente los trabajos tanto del camino como del puente, lo que obligó a las autoridades a nombrar un facultativo que, en compañía de García Conde, realizara un reconocimiento de los daños y las obras a seguir. La persona designada para ello fue el director de escultura de la Academia de Bellas Artes de San Carlos y ya reconocido arquitecto, Ma-

\footnotetext{
35 Idem.

${ }^{36}$ Humboldt, 1983: 465-466.
} 
nuel Tolsá. La decisión fue seguir adelante con las obras, con la demanda de que el puente debía contar con ocho arcos, en vez de los siete considerados inicialmente. Con contratiempos por las condiciones climáticas de la región, finalmente quedó concluida la obra, camino y puente, en 1812 .

La presencia de Tolsá como parte del reconocimiento de 1806 ha llevado a la confusión en varios autores de atribuirle el diseño del puente. La documentación citada demuestra que la autoría es totalmente obra de Diego García Conde.

El Puente del Rey, hoy Puente Nacional, fue una obra crepuscular del virreinato novohispano, uno de los mayores puentes construidos en la Nueva España, y que pese al paso de los años, sin perder su aire colonial e ilustrado se acomodó a las nuevas necesidades del tráfico vial ${ }^{37}$.

En 1809 es nombrado coronel de su regimiento y como tal participará activamente en la defensa de la Corona ante el movimiento de Independencia que estalla en septiembre de 1810 . El $1^{\circ}$ de octubre de ese año es nombrado comandante militar de la provincia de Valladolid, y cuando se encontraba en camino a la capital de la provincia es herido y aprehendido en Acámbaro ${ }^{38}$, junto con el conde de Rul y el intendente de Michoacán, y entregado a Miguel Hidalgo, cabeza de la insurrección ${ }^{39}$. Sin embargo, en el transcurso de la batalla de Aculco, el 7 de noviembre, escapa de los insurgentes tras la derrota que sufren a manos del coronel Félix María Calleja; de esos días como prisionero escribe una «apasionada e inexacta relación de los sucesos ocurridos en el ejército de la independencia, durante el tiempo que duró su aprehensión ${ }^{40}$, citada por Beristaín y Souza.

En el curso de los primeros meses de guerra asciende a mayor, y se le da el mando de la caballería del Ejército del Centro, participando en las batallas de Guanajuato y Puente de Calderón a las órdenes del coronel Calleja; posteriormente, al mando de la División de la Izquierda del Ejército de Centro, participó en diversas acciones de guerra en la región del Bajío y San Luis Potosí, saliendo triunfante siempre ${ }^{41}$. De esa etapa de su carrera es el Plano del ataque dado a los insurgentes en la proximidad del Pueblo del Valle del Maíz, por la División de S. M. al mando del Coronel Don Diego García Conde; la mañana del 22 de marzo de $1811^{42}$ (figura 3).

\footnotetext{
37 González Tascón, 1992, vol. II: 560.

38 Actual estado de Guanajuato.

39 Mora, 1856, vol. 4: 67

${ }^{40}$ Citado en Moncada Maya, 1993: 97.

41 Idem.

${ }^{42}$ Orozco y Berra, 1871.
} 
Figura 3. Plano del ataque dado a los insurgentes en la proximidad Del pueblo del Valle del Maíz, SAn Luis Potosí, 1811

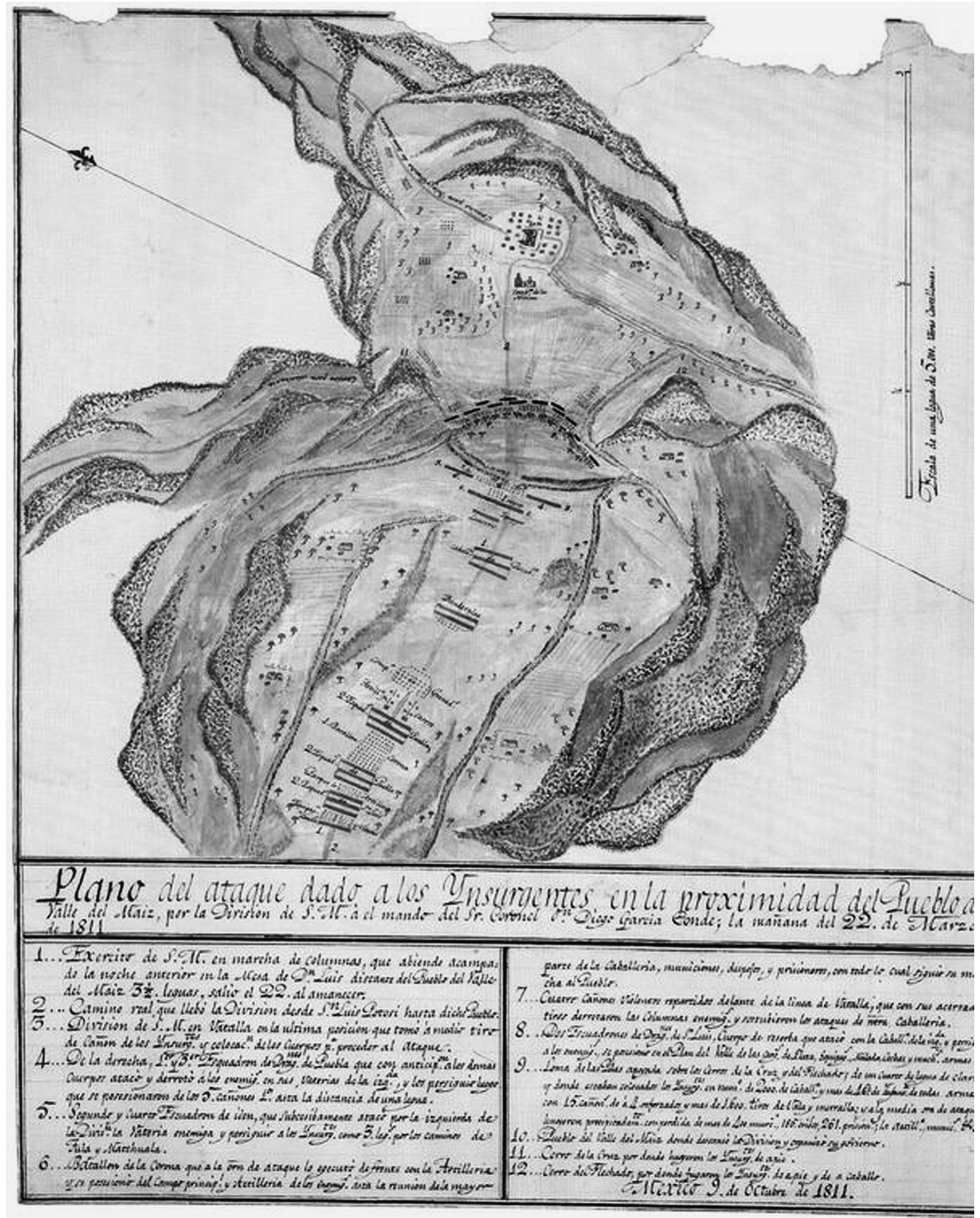

Fuente: Mapas y planos relativos a la Revolución de Independencia de México en el acervo de la Mapoteca Manuel Orozco y Berra del Servicio de Información Agroalimentaria y Pesquera de la Secretaría de Agricultura, Ganadería, Desarrollo Rural, Pesca y Alimentación, México, Varilla OYBSLP01, N. Clasificador 1308-OYB-7242-A. 
Por su desempeño en el transcurso del movimiento insurgente se le ascendió al grado de Brigadier en junio de 1812, y en 1814 es nombrado Gobernador Intendente y Comandante militar de Zacatecas, cargo en el que permanece hasta 1816. Siempre en la defensa de la Corona, asestó duros golpes a los insurgentes, comandando las tropas de la intendencia.

En 1818, fue nombrado por el rey para el gobierno militar y político é Intendencia de la Nueva Vizcaya, que dejó vacante su hermano, el Mariscal de Campo Alejo García Conde al ser nombrado Comandante General de las Provincias Internas de Occidente. Con fecha 6 diciembre de 1818 se recibió en México la orden y se dirigió copia al interesado ${ }^{43}$. En ese mismo año de 1818, su hermano Juan, desde España, solicita para Diego el ascenso de Mariscal de Campo ${ }^{44}$.

En enero de 1822, Diego García Conde solicitó y se le concedió el uso de la Cruz y Placa de la Orden de San Hermenegildo, orden militar a la que pertenecieron el resto de sus hermanos.

Como su hermano Alejo, Diego reconoció en 1821 el Plan de Iguala ${ }^{45}$, y le fue reconocido el grado de General de División y asumió la nacionalidad mexicana. Resulta difícil establecer por qué tomaron esta decisión, toda vez que no se cuenta con algún documento que lo explique. Así, que sólo podemos suponer explicaciones. La más importante es que el Plan de Iguala no pretendía romper en modo alguno sus vínculos con la Corona; aunque por otra parte se debe considerar que al momento del reconocimiento que hace del Plan, Diego García Conde ya contaba con 62 años, llevaba en América más de 30 años, donde había formado una familia, y todos sus hijos habían nacido en Nueva España. Además, se debe considerar que no debía ser fácil regresar a la Península como parte de un ejército derrotado. Pero también hay otro punto importante en su trayectoria militar: cuando dirigió al Ejército del Centro, tuvo a su mando a Agustín de Iturbide, y eso debió contar para tomar la decisión, pues sabía que no habría ninguna represalia por su pasado realis-

${ }^{43}$ AGNM, Reales cédulas originales, vol. 219, exp. 86, fol. 1. El nombramiento estaba dado desde agosto anterior, AGNM, Reales cédulas originales, vol. 219, exp. 112.

${ }^{44}$ Hoja de Servicio..., AGMS, 1776.

${ }^{45}$ El Plan de Iguala o Plan de Independencia de la América Septentrional, fue un pronunciamiento proclamado el 24 de febrero de 1821 por Agustín de Iturbide, y secundado por el general Vicente Guerrero, en la ciudad de Iguala, hoy estado de Guerrero, en el cual se declaraba la Independencia de la Nueva España. El nuevo gobierno se sustentaría en tres principios fundamentales: Religión, Independencia y Unión, que se convirtieron en las «Tres Garantías» que promovió el nuevo ejército, que por esta misma causa se conoció como «Ejército Trigarante». Según este plan, el gobierno que se adoptaría sería el de una monarquía moderada, cuya corona sería otorgada a algún miembro de la casa de los Borbones. 
ta. Todo lo contrario, al organizarse el nuevo Ejército Nacional se le nombró primer Director General de Cuerpo de Ingenieros y fue fundador y director, en 1822, de la Academia de Cadetes $^{46}$, que en sus inicios llegó a contar con 300 alumnos que ocuparon el antiguo edificio de la Inquisición en la ciudad de México; entre la planta de catedráticos se encontraban, como jefe de estudios, el coronel Manuel Mier y Terán, el sargento mayor de brigada y comandante en la provincia de Yucatán José Segundo Carbajal, y el también sargento mayor de brigada José María de Echandia. Desgraciadamente, las condiciones del erario no permitían apoyar de manera decidida este proyecto, por lo que García Conde demandó un apoyo efectivo que sólo se pudo concretar en un apoyo de 250 pesos por única vez, más 50 pesos mensuales ${ }^{47}$.

El 11 de octubre 1823, el presidente Guadalupe Victoria emitió un decreto que transforma la Academia de Cadetes en Colegio Militar, y lo traslada al Fuerte de San Carlos de Perote, donde el número de sus estudiantes llegó a disminuir a diez, razón por la que poco después regresará a la ciudad de México.

Paradójicamente, como reconocimiento a su trayectoria, fue uno de los elegidos para llevar uno de los cordones del féretro de los héroes de la Independencia a los que había combatido ${ }^{48}$.

En marzo de 1825 dirige una comunicación al presidente de la República, general Guadalupe Victoria, en los siguientes términos:

Exmo. Señor: El ciudadano Diego García Conde General de División y Director de Ingenieros con el debido respeto a V.E. expongo hallarme desahuciado de los facultativos que me asisten en mi grave enfermedad y de las buenas esperanzas conviven si salgo por dos o tres meses al pueblo de Tacubaya a restablecerme. Para mí este es un paso de los más sensibles porque en mi larga carrera militar jamás he usado licencia; pero en la disyuntiva de la salud o la muerte, es preciso que me venza tomando todas las medidas para que las clases de matemáticas y asuntos del cuerpo no padezcan el menor atraso, y así continuaré mi correspondencia, a menos que algún asunto ingente me lo impida: Vendré con la mayor frecuencia que pueda, y hasta las relaciones mensuales para el haber del Cuerpo serán autorizadas por mí, por lo que suplico se sirva acceder a esta gracia... ${ }^{49}$

Pese a que se le concede la licencia, Diego no pudo recuperar su salud, y murió en Tacubaya el 1 de mayo de 1825. Fue sustituido interinamente en la Dirección de Ingenieros por Tomás Ramón del Moral ${ }^{50}$.

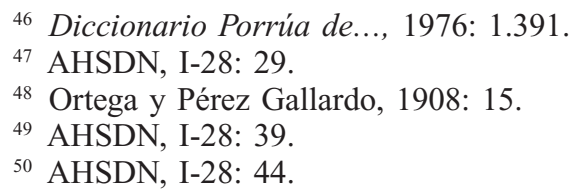




\section{Obra cartográfica}

Podría decirse que gran parte de la cartografía colonial fue resultado del proceso de expansión territorial del virreinato a lo largo de los tres siglos de dominio hispano. Y en ello intervienen numerosos científicos y técnicos, tanto peninsulares como americanos, aunque vale aclarar que la elaboración de mapas no era exclusivo de alguna corporación en particular. Así, para el último tercio del siglo XVIII encontramos entre los cartógrafos a los matemáticos Joaquín Velázquez de León y Diego de Guadalajara y Tello, al naturalista José Antonio de Alzate y Ramírez, a los jesuitas Jacobo Sedelmayer, Francisco Javier Clavijero y Francisco Javier Alegre, a los marinos Juan Pérez, Bruno Ezeta y Cayetano Valdez y a los militares Carlos de Urrutia y Félix María Calleja. Sin embargo, dado que entre las actividades sustanciales de los ingenieros militares se señalaba la intervención territorial a través del diseño y construcción de obras públicas, la cartografía de las mismas fue una de las actividades fundamentales y es en ellas que se destaca la labor cartográfica de Diego García Conde.

Ya señalamos líneas arriba que en 1792 se le encomendó a Diego García Conde la realización de un plano de la ciudad de México, sin duda su obra más reconocida y que ha trascendido hasta la actualidad. Tal vez la mejor forma de comprender la importancia y significado del mapa realizado por García Conde sea considerar el comentario de A. Moreno Toscano: «... hacer un mapa o plano es, finalmente, apropiarse simbólicamente de un territorio. La gran paradoja que encierra el plano de García Conde es que, si en su origen se pensó como documento práctico, su factura final expresó con arte el orgullo criollo por la Ciudad de México» ${ }^{51}$.

Esto se percibe de inmediato, con la primera impresión del plano de la ciudad, que muestra con gran claridad la representación de su tramado, el trazo de una retícula casi perfecta, de la Plaza Mayor hacia la periferia, donde incluye con gran detalle la localización de importantes edificaciones, plazas, paseos, parroquias, conventos, hospitales y aún elementos de menor magnitud, pero que en conjunto muestran la conformación de una gran ciudad (figura 4).

Calles y avenidas que muestran un trazo simétrico con dimensiones más o menos regulares, seguidas de las de menor magnitud hasta perderse en los extremos de la traza urbana, a través de las cuales es posible identificar los límites de la mayor actividad de la ciudad así como la movilidad de sus habitantes; para posteriormente formar pequeñas manzanas, que semejan unas

${ }^{51}$ Moreno Toscano, 2002: 9. Aunque es necesario recordar que García Conde no era criollo, sino que era español peninsular. 
islas distribuidas en los extremos, de forma lineal hacia el norte y oeste, y más dispersas y de menor simetría hacia el sur y oriente, que sin duda vislumbraba ya el comienzo del proceso de urbanización que seguiría la ciudad en los siguientes decenios.

El trazo de las vías de acceso a la ciudad es fácilmente identificable, permitiendo ubicarse espacialmente en el entramado urbano y en los extremos del área citadina, con elementos que las distinguen, como el arbolado, y que llegaban a las garitas que rodeaban a la ciudad.

La representación de la periferia, en partes vacía y en otras con cubierta arbórea o parcelas de cultivo en las partes más extremas, le imprime el contexto del área de influencia de la ciudad, así como la confirmación de la línea divisoria rural-urbana, principalmente hacia el norte-noroeste de la ciudad.

Las viñetas, cuadros listados de los cuarteles y el nomenclátor de calles complementan la sensibilidad, habilidad y visión de conjunto de García Conde para demostrar lo que quiere resaltar en su plano general de tan importante asentamiento urbano.

El detalle de la parcelación en la porción occidental de la ciudad es muy cuidada, invita a realizar un minucioso recorrido para calcular posiciones, dimensiones y hasta clasificaciones. En el mismo caso se presenta la porción oriental, donde la traza comienza a ser más irregular, pero son registrados a detalle cada bloque de manzanas, que aun con sus variables dimensiones y formas geométricas más irregulares, todas aparecen identificadas aun cuando se representen como islas dentro del entramado de las calles de la gran ciudad.

En los extremos norte y sur, sobre todo en el norte, la ciudad muestra el continuum urbano lo que pone en evidencia un crecimiento de la ciudad hacia esa porción principalmente a lo largo de la vía principal de acceso y conexión con la zona central del país. La distribución de las manzanas es irregular en cuanto a dimensiones, formas, pero en la mayor parte de los casos ya conformando asentamientos de manera aislada, parecieran como islas, desde pequeñas dimensiones hasta algunas de mayores tamaños, que con el paso de los años, y siglos, vendrían a conformar el principal destino del crecimiento urbano periférico, y que pese a esa dispersión que le caracterizaba, García Conde respeto en el trazado del plano.

El plano va acompañado de dos viñetas de la ciudad de México, colocadas en la parte inferior del mismo. La viñeta del lado izquierdo representa la «Vista I. de Levante desde el camino nuevo de Vera-Cruz», y la del lado derecho la «Vista II. de Poniente desde el camino de Chapultepec».

En las vistas se observa una visión de la panorámica de la ciudad, destacando la gran cantidad de cúpulas de los templos y algunas características de 
Figura 4. Plano general de la Ciudad de MÉxico, 1807, donde se observa la Plaza Mayor. (Fragmento)

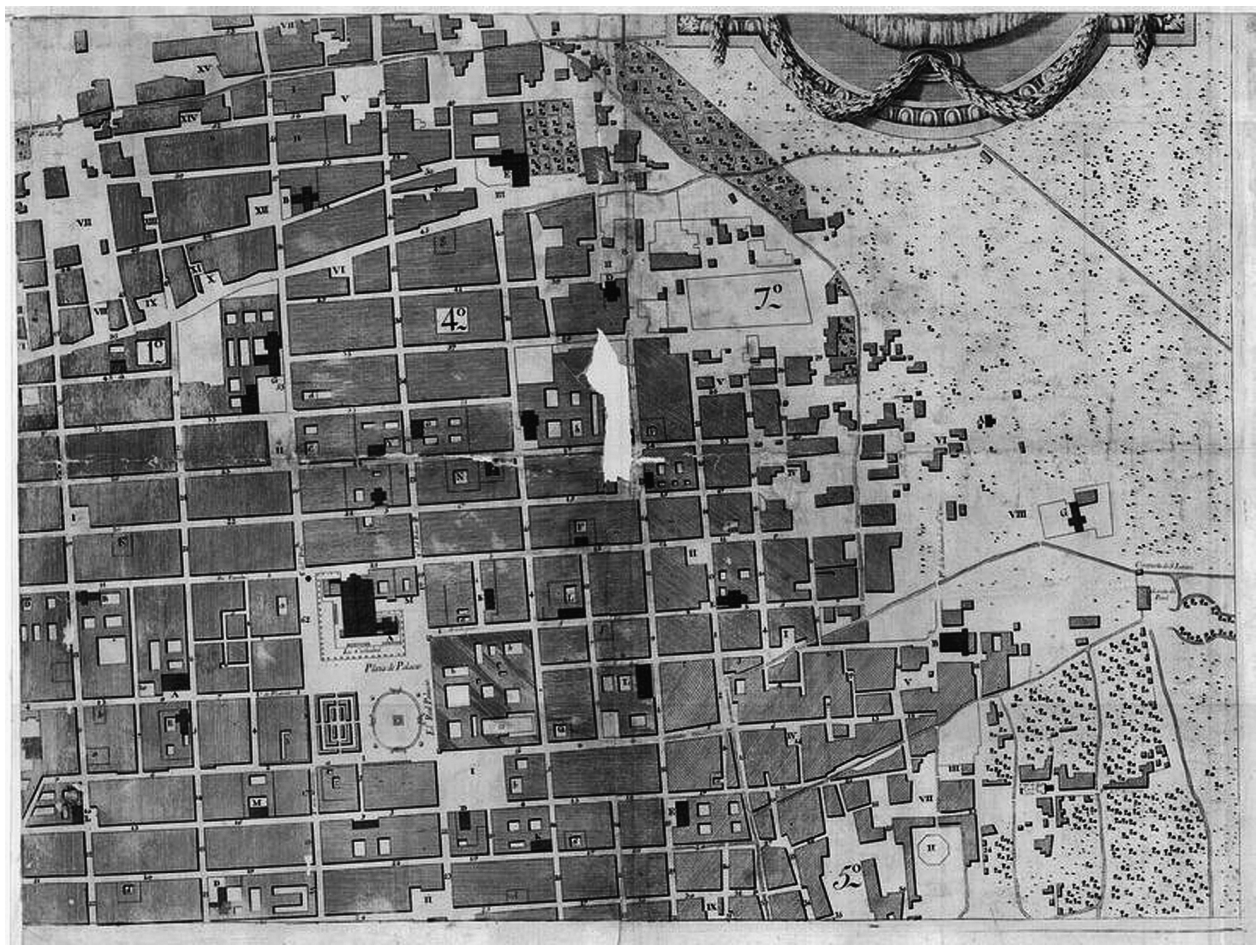

Fuente: Mapas y planos relativos a la Revolución de Independencia de México en el acervo de la Mapoteca Manuel Orozco y Berra del Servicio de Información Agroalimentaria y Pesquera de la Secretaría de Agricultura, Ganadería, Desarrollo Rural, Pesca y Alimentación, México, Varilla OYBDF02, N Clasificador 929-OYB-7252-A.

los barrios. Asimismo, alguna de ella permite visualizar el tipo de transporte que pudo servir para conectar a la ciudad con otras poblaciones, como la carreta que aparece en la Vista I de Levante, así como también la actividad productiva de sus pobladores, como es el caso de la agricultura, con los dos personajes que ahí se representan.

Otra forma de identificar características rural-urbanas en la Vista II de Poniente sería la representación de lo que podría parecer parte de una hacienda y al lado la casa-habitación de los trabajadores de la misma, y algún granero o taller para el abastecimiento de la hacienda; además de que se muestra parte de la vegetación nativa de la periferia de la ciudad y algunas superficies de cultivo. Todo ello permite darle vida al plano. 
La descripción de la conformación de los cuarteles es amplia y con todos los elementos a considerar para que no quede ningún elemento fuera de tomarse en cuenta. Las notas en la parte superior, así como la representación de la escala en la parte inferior derecha, además de adornar el plano, permiten identificar los detalles para dar una lectura lo más acertada posible de lo que conforma e identifica a la gran Ciudad de México.

La valoración de este plano se ratifica con las observaciones que hace E. Trabulse respecto a la impresión del mismo, varios años después de su levantamiento:

El valor de este Plano desborda asimismo el aspecto puramente científico ya que en su elaboración participaron dos de los más distinguidos artistas del siglo XVIII: Rafael Ximeno y Planes, quien lo dibujó, y José Joaquín Fabregat, quien lo grabó. Fue Manuel López López quien tuvo a su cargo la pesada tarea de estamparlo. El Plano está grabado en cobre, con una "escala de 1000 varas castellanas" (1:36000) y mide 207 por $153 \mathrm{~cm}$. Lo que resulta excepcional es que (hasta donde sabemos) sólo un ejemplar conocido de este raro mapa haya sido iluminado a la acuarela. Un dato adicional, no confirmado, señala que un indígena Santiago Nezahualpilli, quien era un excelente topógrafo, ayudó a García Conde en el levantamiento del plano. Desde la fecha de su publicación el Plano ha sido reproducido varias veces en diversos tamaños, la primera en $1810 \mathrm{y}$, como muchos de los planos coloniales, a menudo ha sido utilizado con fines puramente decorativos. En Europa fue conocido, y admirado, desde 1824, cuando William Bullock lo publicó en su obra de viajes en México, y desde entonces ha sido reconocido como una obra mayor de la cartografía colonial de México ${ }^{52}$.

Una mejor forma de terminar con la descripción de este valioso plano es lo que asienta Toussaint cuando afirma que: «el rey de los planos de México, el de García Conde, une, a la excelencia del levantamiento y del trazo, la de la ejecución artística, el grabado en cobre, el cual por su técnica, su belleza y su tamaño, resulta excepcional» ${ }^{53}$.

Mientras que, en palabras de Orozco y Berra:

... el plano de García Conde es el más grande y mejor de cuantos han visto la luz pública en México... El plano de García Conde vino a fundar escuela; la mayor parte de los planos que le siguieron lo reconocen por origen; unos copiaron francamente, mientras otros dicen que aumentaron o corrigieron; estos confiesan la filiación, mientras aquellos la callan; pero todos corresponden a la misma familia, y dejaron el trabajo con pocas variantes, casi en el punto de partida ${ }^{54}$.

\footnotetext{
${ }^{52}$ Trabulse Atala, 2002: 40-42.

53 Ibidem: 40.

${ }^{54}$ Orozco y Berra, 1867: 10.
} 
Orozco y Berra refiere que al menos diez mapas sobre la ciudad de México publicados entre 1811 y 1865 son copias del mapa de nuestro personaje:

> Plan general de la ciudad de México, levantado por el teniente coronel D. Diego García Conde en el año de 1793, y grabado en miniatura en Londres, por Eduardo Mogg, el año 1811.

- Plan de la Ville de México dressé sur les lieux par le colonel comte D. Diego García, 1824.- Pequeño, grabado en el -Atlas Historique avec l'explication des planches, París, 1831,-- del viaje de M. Bullok.

- Plano general de la ciudad de México, levantado por el teniente coronel D. Diego García Conde en el año de 1793. Aumentado y corregido en lo más notable por el teniente coronel retirado D. Rafael María Calvo, en el de 1830.- Grabado en Nueva York.

- Plano general de la ciudad de México, aumentado y corregido en lo más notable por el teniente coronel retirado D. Rafael María Calvo, en Enero de 1837.- Pequeño, sobre plomo o madera; en el Calendario de Cumplido para 1838.

> Plano general de la ciudad de México, 1849. -Hállase en París en casa de Bauerkeller y C.- Realzado y colorido; de efecto y poca utilidad.

> Plano general de la ciudad de México, formado según los datos más recientemente adquiridos, para servir a la Guia de Forasteros, publicada por el Sr. general Juan N. Almonte. Año de 1853. -Litografía.

> Plano general de la ciudad de México. Año de 1858.- Propiedad de Rosa y Bouret.-Litografiado en París, en el Manual del Viajero en México, \&c.

> Plano general de la ciudad de México, Año de 1858.- México, imprenta litográfica de Decaen, pequeño, colorido o negro; se encuentra suelto y en la obra intitulada México y sus alrededores.

> Plano general de la capital de la República Mexicana, 1860.- Para servir a la obra intitulada el Viajero en México, publicación de Juan N. del Valle.- Litografía.

> Plano general de la ciudad de México, 1861. -México, imp. litog de Decaen, editor.- En escala cuádruple del de 1858. Llevando por detalle el Distrito de México ${ }^{55}$.

El año de 1798 fue de mucha actividad en su labor de ingeniero voluntario. Por una parte, el Consulado de Veracruz consiguió el apoyo del virrey Azanza para que un nuevo camino hacia la ciudad de México, que en térmi-

55 Idem. Del último mapa existen ediciones sin cambios en 1863, 1864 y 1865. 
nos generales seguía el trazado del ya existente, se construyera por la ruta de Jalapa, alternativo a la ruta de Orizaba y Córdoba, quedando como director de la obra Diego García Conde. En el curso de ese año levantó una serie de planos sobre diversos aspectos de dicha obra, que se localizan en diversos ramos del Archivo General de la Nación, en la ciudad de México. Dos son mapas generales, donde sin duda aprovecho el levantamiento que un año antes hiciera acompañando a Miguel Constanzó: Plano en el que se representa la dirección de los dos caminos que bajan de México para Veracruz, por los distintos rumbos de Orizaba y Xalapa, en la parte que media entre la Sierra y la Costa, y el Plano topographico del Camino nuevamente descubierto que saliendo de la Villa de Orizaba con dirección a la Ciudad de México encumbra la Sierra del Volcán, por el paraje nombrado Lomaverde ${ }^{56}$ (figura 5).

Un perfil del camino de México a Veracruz, muestra la necesidad de construir numerosos puentes a lo largo de ruta, ya sea para cruzar barrancos, ya para evitar arroyos y ríos de muy diverso caudal. Es precisamente durante la dirección de las obras por García Conde que se considera la construcción de al menos cuatro puentes en la ruta:

- Plano y vista que deberá tener el puente proyectado en el río de la Antigua, enfrente de la Ventilla, Veracruz.

- Plano y vista que deberá tener el puente que se ha de construir en el arroyo Copále, Puebla.

- Plano y vista que deberá tener el puente que se ha de construir en río de San Juan, Puebla.

- Plano y vista que deberá tener el puente que se ha de construir en el arroyo llamado Paso de Ovejas, Veracruz.

Como complemento, levantó el Plano y elevación de la casa para el gobernador del peaje Puebla de los Ángeles y el plano de la Casa para los guardas del camino, en Puebla ${ }^{57}$.

Humboldt recorrió estos caminos y nos dejó una detallada, aunque breve, descripción del mismo:

El soberbio camino que hace construir el consulado de Veracruz, desde esta ciudad hasta Perote, podrá competir con los del Simplón y del Mont Cenis: es ancho, sólido y de un declive muy suave. No se ha seguido la delineación del antiguo

\footnotetext{
${ }^{56}$ Ambos mapas se localizan en AGNM, Fomento Caminos.

${ }^{57}$ Tanto los planos de los puentes como de las construcciones se localizan en el Centro de Información Gráfica del AGNM, signatura P2-C1-F7 al P2-C1-F10.
} 
Figura 5. Plano del Puente sobre el arroyo Paso de Ovejas, 1798

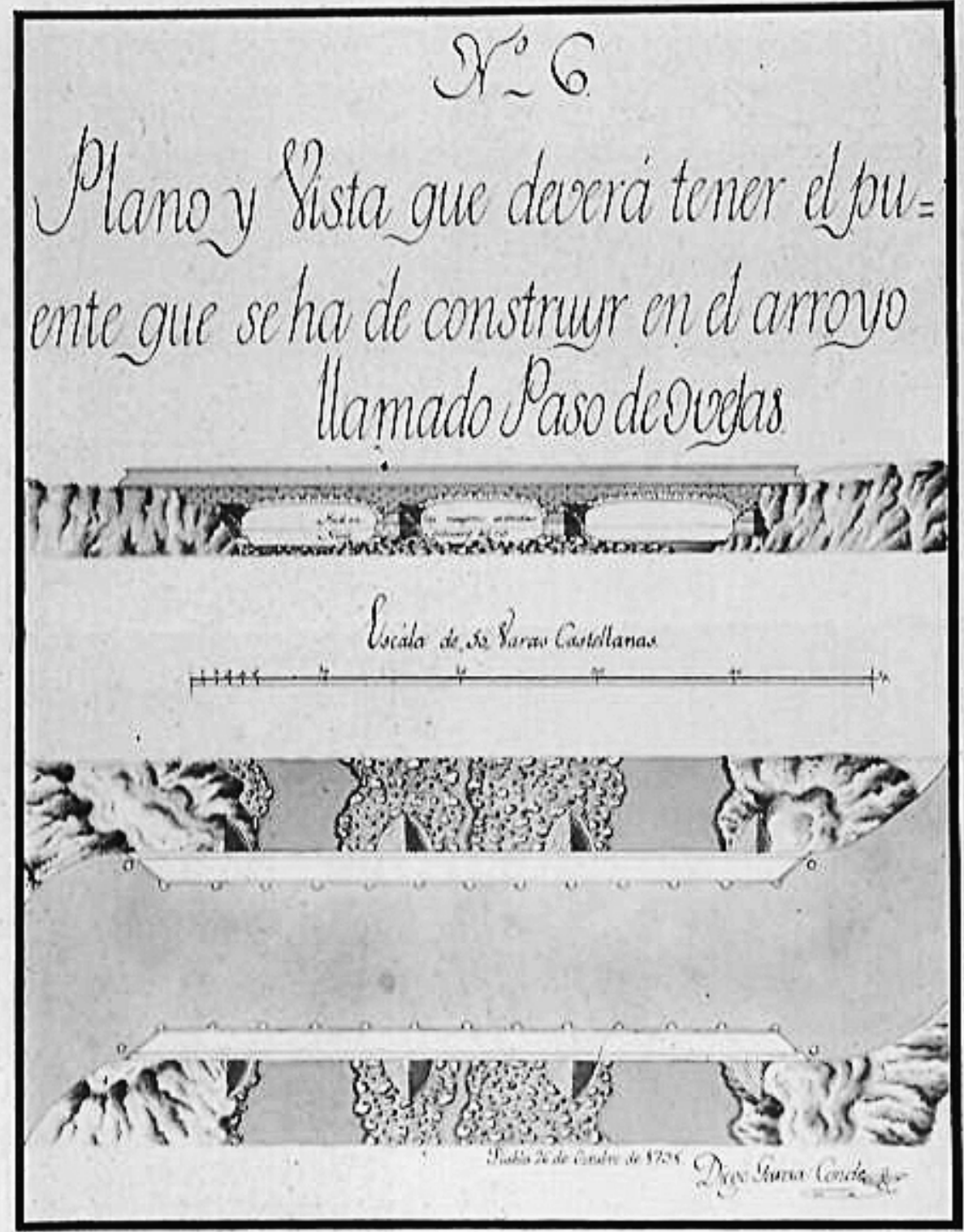

Fuente: Archivo General de la Nación, México DF, Centro de Información Gráfica, P2-C1-F9. 
camino que era muy angosto, empedrado con pórfido de basalto, y que según parece fue construido hacia la mitad del siglo XVIII; se han evitado cuidadosamente las subidas rápidas; y luego que los carros substituyan para el transporte de los géneros a las recuas de caballería, cesarán las quejas contra el ingeniero por haber alargado demasiado el camino. Esta obra costará probablemente más de tres millones de pesos; pero se debe esperar que una empresa tan hermosa y útil no padecerá interrupción (...) Durante mi residencia en Jalapa, en el mes de febrero de 1814 (sic por 1804), se había empezado el nuevo camino que se construye bajo la dirección del señor García Conde, en los parajes que presentan las mayores dificultades... Se ha proyectado poner columnas de pórfido todo a lo largo del camino, para señalar, además de las distancias, la altura del terreno sobre el nivel del Océano. Estas inscripciones, que no se encuentran en ninguna parte de Europa, ofrecerán un particular interés al viajero que sube por la falda oriental de la cordillera; porque le tranquilizarán anunciándole que se acerca a aquella región feliz y elevada, a donde ya no debe temer el azote del vómito prieto o fiebre amarilla ${ }^{58}$.

\section{Los descendientes de Diego García Conde}

Como es común en estos casos, muy poco se sabe de la vida personal de los militares; sin embargo, el hecho de que necesitaran autorización real para contraer matrimonio nos permite saber que hacia marzo o abril de 1799, Diego García Conde contrajo nupcias con María Luisa Maneyro, hija del teniente coronel del Veterano Cuerpo Provincial de Dragones de Puebla, en el que servía. En 1774 se estableció que los oficiales tenían «prohibido casarse sin licencia Real y sin el consentimiento del maestro del campo, de igual manera no se admitían oficiales casados de Coronel abajo en los Regimientos de Infantería, Caballería, Dragones, Ingenieros, estado Mayor y Artillería, ni pueden gozar sueldos de tales los que sean admitidos solteros y se casen, también se les aplique lo mismo, aunque sea con mi Real permiso» ${ }^{59}$. Sólo el Director o el Inspector podían dar licencia para el matrimonio, a condición de que la contrayente fuera «de tal calidad y circunstancia que merezca casarse con un oficial (...) La calidad (...) había de consistir de que fuesen hijas de padres «nobles o hidalgos〉 o, por lo menos, del <estado llano〉, de hombres, buenos, honrados y limpios de sangre, que justificasen una dote de 20.000 reales de vellón, las primeras y, de 50.000 las segundas ${ }^{60}$. Aquellos oficiales que no cumplieran con la regulación podían perder el empleo y el derecho de legar pensión.

\footnotetext{
58 Humboldt, 1983: 465.

59 Diez Muñiz, 1969: 61.

${ }^{60}$ Idem.
} 
De este matrimonio nacieron siete hijos: José María, Ceferino, Regina, Loreto, Diego, Tomás y Ana. De ellos sabemos que tres de los hombres siguieron el camino de las armas, Infortunadamente quedo viudo, y hacia 1816-1818 contrajo segundas nupcias con María Luisa de Cuéllar, con quien procreó 5 hijos más, tres varones -José, Juan y Manuel-y dos mujeres -Refugio y Cristina-. Poco después de su muerte, en agosto de 1826, su viuda solicita al gobierno acepte como cadetes a sus hijos, ¡de 7, 3 y 2 años!, «... quienes manifiestan desde su tierna edad particular inclinación a emprender la carrera militar a imitación de su benemérito padre...». En realidad, lo que la viuda deseaba era obtener un ingreso que le permitiera sobrevivir, pues el monte pío que dejó García Conde, de apenas 29 pesos mensuales, pasaban en su mayoría a los hijos del primer matrimonio ${ }^{61}$.

Tuvieron que pasar 11 años para que doña María Luisa Cuéllar tuviera una respuesta positiva. En noviembre de 1837 se le comunica que el C. Presidente Anastasio Bustamante «se ha servido declararle el monte pío de setecientos cincuenta pesos que es el que le corresponde, con arreglo a la citada ley de 22 de enero de 1830, y desde cuya fecha debe abonársele a la Sra. interesada» ${ }^{62}$.

Únicamente disponemos de información muy desigual de algunos de los descendientes de su primer matrimonio. Así sabemos que José María, el hijo mayor, nació en la ciudad de México el año de 1801. En la página 43 del Libro 21 de Bautismos de la Parroquia de Santa Catalina Virgen y Mártir ${ }^{63}$, se lee:

En la ciudad de México: en 18 de Noviembre del año del Señor de mil ochocientos uno: En esta Parroquia de Santa Cathalina Virgen y Mártir, Yo, el Br. Dn. José Carrillo, Capellán del Regimiento de Dragones de México, bauticé solemnemente a José María Gregorio Francisco Xavier, nació el día diez y siete, hijo legítimo de D. Diego García Conde, natural de Barcelona, Sargento Mayor de dicho Regimiento, y de D. María Luisa Maneyro, que viven en la calle de San Lorenzo número nueve. Nieto por línea paterna de D. Alejo García y de D. Teresa Conde, naturales de Ceuta: y por la materna de D. Ignacio Maneyro y de D. Antonia Regina Rodríguez. Fue su madrina D. María Antonia Fernández... ${ }^{64}$

La hoja de servicio que existe en el Archivo Histórico de la Secretaría de la Defensa Nacional, nos permite reconocer una amplia carrera en el ejército, donde sin duda el apellido influyó, pero también la preparación que alcanzó. Así, a los 13 años, en abril de 1814, se incorporó como cadete en el

\footnotetext{
${ }^{61}$ AHSDN, I-28: 48.

${ }^{62}$ AHSDN, I-28: 53.

${ }^{63}$ AHDSN, XI.III/2-882.

${ }^{64}$ AHDSN, 089.
} 
batallón Mixto Provincial de Zacatecas, donde llegó a subteniente y en 1817 pasa al Batallón ligero de Zacatecas. En 1818 asciende a teniente y en 1824 a capitán. Participó en la lucha de insurgencia, y a partir de agosto de 1821 estuvo bajo las órdenes de Agustín de Iturbide, cuando éste decide tomar el partido del Plan de Iguala. Ya en el ejército del México Independiente estuvo a disposición en el Depósito del Ejercito Imperial (1821), en el Regimiento de Línea (1821-1823), en el Batallón de Línea (1823-1831), y en el Batallón Activo de Toluca (1833-1834). En este último destino recibió su ascenso a teniente coronel.

Posteriormente estará destinado en el Batallón Activo de Tlaxcala (1834), desde donde marcha en defensa de Veracruz en contra de los franceses, en 1838, y en el Regimiento de Infantería de Línea (1839) en que asciende a coronel. En el enero del año de 1842 se le destina como secretario de la Sala de Ordenanza de la Suprema Corte Marcial, para en mayo del 43 regresar a la vida militar al incorporarse como General de brigada al 1er. Regimiento de Infantería Activo de México, en el Batallón de Granaderos de la Guardia (1845).

En julio de ese último año vuelve a la Suprema Corte Marcial, donde permanece siete meses; durante esta etapa solicita su separación del servicio por motivos de salud: «Penetrado hasta la evidencia de que el mal estado de mi salud por los frecuentes ataques de gota que padezco no me permiten prestar ningún servicio activo, pues que tanto me daña el frío como el sol y especialmente la humedad impidiéndome en lo absoluto poder montar a caballo; con objeto de no engañar a la Nación con una plaza verdaderamente supuesta, me he resuelto a pedir mi separación del servicio...» ${ }^{65}$.

No debió aceptarse esta solicitud, toda vez que continúa como secretario general de la Corte Marcial. Además, poco después el gobernador de la ciudad de México solicita se le comisione en el «Batallón Fijo de México para el alistamiento de las fuerzas que ha de levantarse en la capital de Defensores de la Independencia y de las Leyes», ya en el conflicto bélico en contra de los Estados Unidos. Poco después se traslada al Batallón Activo de Aguascalientes (1846), donde se le nombra Coronel comandante, y en septiembre de ese año se incorpora en el Estado Mayor del Ejército del Norte y posteriormente, a partir de diciembre, comanda el Regimiento de Infantería, de donde por diferencias con la tropa que se niega a marchar a Monterrey, para socorrer a la ciudad, en la guerra contra los Estados Unidos, decide marchar sólo. Participó en la campaña contra los americanos en 1847, para después quedar al mando del Cuerpo de Inválidos, de 1850 a 1854 . En febrero de este año le quitan el mando del Cuerpo y hace uso del retiro.

\footnotetext{
65 Idem.
} 
A lo largo de su carrera militar intervino en numerosas acciones militares, que le valieron distintos reconocimientos: «Un escudo de distinción por el sitio y toma de Comajá en 1817. El grado de teniente y un escudo de distinción por el sitio y toma del Fuerte de San Gregorio en 1818, donde salió herido. El de teniente coronel del ejército en virtud de la ley de 15 de marzo de 1832, por haberse distinguido en la acción de Jolome el tres del mismo mes y año. Un escudo de distinción por la pacificación de Puruándiro, y otro escudo por la pacificación de Guanajuato.... ${ }^{66}$.

Pero sin duda alguna, los mayores reconocimientos fueron la Cruz y placa de 1a. Clase concedida por su constancia en el servicio y «El título de Benemérito del Estado de Puebla dado por la legislatura del mismo, a la vez de darle un voto de gracias por el celo con que conservó la tranquilidad pública durante su administración».

Desempeñó múltiples cargos a lo largo de su vida, destacando el haber sido, durante tres años, director del Primer Departamento del Estado Mayor General; otros tres años fue Secretario de las Comandancias Generales de México y Puebla, durante once meses dirigió la Comandancia General de Tamaulipas. Desempeñó en dos ocasiones el cargo de Ministro del Supremo Tribunal de Guerra. En 1855 es nombrado Gobernador y Comandante General de México, cargo en el que apenas dura del 15 de octubre al 25 de noviembre, pues pasa como gobernador y Comandante Militar de Puebla. Durante la presidencia de Ignacio Comonfort formó parte de su gabinete ocupando la cartera de ministro de Guerra y Marina, de septiembre de 1857 a enero de 1858.

De su vida personal conocemos muy poco. Se sabe que en julio de 1833 «solicita se instruya información que acredite la vida y costumbre de la Srta. Catalina Humana, residente en la capital», con fines matrimoniales; ella era hija de Patricio Humana, oficial primero de la Secretaría del Virreinato (sic), y de María Bernarda Vallejo ${ }^{67}$. Otro dato: en 1842 solicita licencia temporal, que se le concede por un año, para trasladarse a Europa, pues padecía una «afección gotosa reumatismal de lo más rebelde», por lo que se va a tomar baños minerales. Durante ese viaje marcha junto con él, su hermano menor, el capitán retirado, Diego García Conde, quien era Comandante de Escuadrón, y Oficial $1^{\circ}$. de la Secretaría de la Sala de Ordenanza de la Corte Marcial. Retirado a la vida privada, murió en la ciudad de México en 1878.

Las únicas referencias que poseemos de Tomás García Conde señalan que fue Comandante de Escuadrón y recibió la «medalla de honor concedida por el

\footnotetext{
${ }^{66}$ Idem.

${ }^{67}$ Ortega y Pérez Gallardo, 1908, vol. III: 15.
} 
decreto de 11 de noviembre de 1847 », a los defensores de Chapultepec ${ }^{68}$; por otra parte, se sabe que estuvo en la Plana Mayor del Colegio Militar, donde ocupó los cargos de secretario (1843), Jefe de instrucción (1846 a 1857, con algunas interrupciones) y profesor de física $(1850)^{69}$. Finalmente, sólo sabemos que Ceferino García Conde alcanzó el grado de coronel $^{70}$.

Información sobre sus hijas nos indica que Regina casó con su primo Rafael y Loreto con su primo Pedro García Conde, ambos hijos de Alejo García Conde ${ }^{71}$.

\section{CONSIDERACIONES FINALES}

La investigación que deriva de este ilustre personaje no podría entenderse sin considerar que la herencia, tanto en línea ascendente como descendente, fue un hito que marcó la historia general de la familia García Conde. Sin duda es un caso particular el que los cuatro hijo del teniente coronel de infantería y sargento mayor Alejo García Conde alcanzaran los más altos grados en la estructura militar, cargos y reconocimientos, independientemente que sirvieron a la Corona, dos en España y los otros dos en el nuevo continente.

En el caso particular de Diego García Conde, los principales aportes que quedan, gracias a sus conocimientos en matemáticas, arquitectura y geografía, son el camino de Veracruz a Jalapa, el puente del Rey sobre el río de La Antigua y, su legado más conocido, el mapa de la ciudad de México, que por su calidad, belleza y precisión sirvió de ejemplo para subsecuentes mapas de la misma. Y, sin embargo, debemos reiterar que aun cuando colaboró con ingenieros militares tan destacados como Miguel Constanzó y Manuel Agustín Mascaró, nunca se integró formalmente al Cuerpo de Ingenieros, permaneciendo siempre como ingeniero voluntario ${ }^{72}$.

Por su trayectoria en el servicio, por su participación en la construcción de diferentes obras, así como en los cargos que le fueron encomendados, al reconocer el Plan de Iguala y asumir la nacionalidad mexicana, se le reconoce en el nuevo Ejército Nacional al ascenderle a General de División y

\footnotetext{
${ }^{68}$ Carreño, 1972: 82.

${ }^{69}$ Véase Archivo Histórico de la Secretaria de la Defensa Nacional, Apuntes históricos y personales del Colegio Militar Mexicano. Años de 1824-1884, (copia mecanografiada), expediente Tomás García.

${ }^{70}$ Ortega y Pérez Gallardo, 1908, vol. III: 17.

${ }^{71}$ Idem.

72 Situación similar vivió otro destacado ingeniero voluntario, Diego García Panes, quien ha sido estudiado por Cisneros Guerrero, 1995.
} 
nombrarle, además, Director del Cuerpo de Ingenieros con carácter de fundador y ser el primer director de la Academia de Cadetes, antecedente del Colegio Militar. Reconocimientos que marcan la trascendencia de su actuar como militar al servicio de la nación y para la formación de las nuevas generaciones de cadetes.

Los descendientes de Diego García Conde también aprovecharían la condición de tan importante herencia en la milicia para desempeñarse en la vida pública de México, y haciéndolo de forma excepcional, según marcan las fuentes.

Aun cuando se conocen partes importantes en la vida pública de Diego García Conde, falta por cubrir y desentrañar detalles de la vida privada que quedan a la interpretación en cuanto a las relaciones con sus padres, sus hermanos, sus esposas e hijos. Si bien en el caso de los varones fue casi condición sine qua non el que continuaran el ejemplo y trayectorias de los García Conde, en el caso de las hijas, de algunas de ellas por lo menos, ahora podemos saber que mantienen ese vínculo con la milicia al contraer matrimonio con sus primos, que también eran militares.

Asimismo cabe hacer notar el compromiso con el cumplimiento del deber, cuando al dirigir su petición al Gral. Guadalupe Victoria para solicitarle una licencia que le permitiese el restablecimiento de su salud, muestra su pesadumbre por tener que desligarse de la actividad, manifestando su preocupación porque su ausencia afectará la preparación de sus clases de matemáticas y los asuntos del cuerpo.

Casos como el de los hermanos García Conde que deciden permanecer en América, asumiendo una nueva nacionalidad, no son raros. Sin duda debemos entenderlos por los muchos años que pasaron en su destino americano. No olvidemos que Alejo García Conde pasó 42 años en América y Diego 37. Establecieron vínculos familiares, y sus hijos se integraron a la estructura política del México Independiente.

Por ello, consideramos es de interés estudiar la vida y obra de Diego García Conde. Su importante legado a la historia de las obras públicas, a la geografía a través de sus trabajos cartográficos, constituyen un legado que se enmarca dentro de la gran obra de los ingenieros militares en América en general y en México en particular. 


\section{BIBLIOGRAFÍA}

Almada, Francisco R., Diccionario de historia, geografía y biografía sonorenses, Chihuahua, México, Ruiz Sandoval, 1952.

Alonso Báquer, Miguel, Aportación militar a la cartografía española en la historia contemporánea, Madrid, CSIC, 1972.

Beristáin de Souza, José Mariano, Biblioteca hispano americana septentrional, 3 vols., Amecameca, México, Tip. del Colegio Católico, 1883.

Carreño, Alberto María, El Colegio militar de Chapultepec, 1847-1947, México, Ediciones Victoria, 1972.

Cisneros Guerrero, Gabriela, “Diego García Panes y Abellán, un ingeniero militar en la historia indiana", tesis para obtener el título de Licenciada en Historia, Facultad de Filosofía y Letras, UNAM, 1995.

Diccionario Porrúa de historia, biografía y geografía de México, México, Edit. Porrúa, 1976.

Diez Muñiz, Evangelino, "El matrimonio de militares en España", Revista de Historia Militar, XIII/2 (Madrid, 1969): 57-87.

González Tascón, Ignacio, Ingeniería española en Ultramar, 2 vols., Madrid, CEHOPU/CEDEX/MOPT/Colegio de Ingenieros de Caminos, Canales y Puertos, 1992.

Humboldt, Alejandro de, Ensayo Político sobre el Reino de la Nueva España, México, Ed. Porrúa, 1983.

Instrucciones y Memorias de los Virreyes Novohispanos, 2 vols., Estudio preliminar, coordinación, bibliografía y notas de Ernesto de la Torre Villar, México, Ed. Porrúa, 1991.

León García, María del Carmen, "El camino México-Toluca. Proyecto del ingeniero militar Manuel Agustín Mascaró. Nueva España, 1791-1795”, Scripta Nova, VI/123 (Barcelona, 15 de septiembre de 2002). http://ub.es/geocrit/sn/sn-123.htm (Fecha de verificación: 13 de mayo de 2016).

Moncada Maya, José Omar, "Miguel Constanzó y el reconocimiento geográfico de la costa de Veracruz de 1797", Suplemento de Anuario de Estudios Americanos sección Historiografía y Bibliografía, XLIX/2 (Sevilla, 1992): 31-64.

Moncada Maya, José Omar, Ingenieros Militares en Nueva España. Inventario de su labor científica y espacial Siglos XVI -XVIII, México, Instituto de Geografía, UNAM, 1993.

Moncada Maya, José Omar, El ingeniero Miguel Constanzó. Un militar ilustrado en la Nueva España del siglo XVIII, México, Instituto de Geografía, UNAM, 1994. 
Moncada Maya, José Omar, "Milicia y saber. La familia García Conde en el México Independiente", María Luisa Rodríguez-Sala (coord.), Del estamento ocupacional a la comunidad científica: astrónomos-astrólogos e ingenieros (siglos XVII al XIX), México, Instituto de Investigaciones Sociales-Instituto de Geografía-Instituto de Astronomía-Centro de Investigaciones Interdisciplinarias en Ciencias y Humanidades, UNAM, 2004: 173-214.

Moncada Maya, José Omar, "El 'Puente del Rey' sobre el río de la Antigua", Chantal Cramaussel (ed.), Rutas de la Nueva España, México, El Colegio de Michoacán, 2006: 63-95.

Mora, José María Luis, Méjico y sus revoluciones, 4 vols., París, Librería de Rosa, 1856.

Moreno Toscano, Alejandra, "La ciudad vista desde el cosmos", Una visión científica y artística de la Ciudad de México. El plano de la capital virreinal (1793-1807) de Diego García Conde, México, Centro de Estudios de Historia de México, Condumex, 2002: 89-99.

Navarro García, Luis y Antolín Espino, Ma del Pópulo, "El virrey Marqués de Branciforte (1794-1798)", José Antonio Calderón Quijano (dir.), Los Virreyes de Nueva España en el reinado de Carlos IV, Sevilla, Escuela de Estudios Hispano-americanos, 1972, vol. I: 369-625.

Orozco y Berra, Manuel, Materiales para una Cartografía Mexicana, México, Sociedad Mexicana de Geografía y Estadística, 1871.

Ortega y Pérez Gallardo, Ricardo, Historia genealógica de las familias más antiguas de México, 3 vols., México, Imprenta de A. Carranza y Comp., 1908.

Trabulse Atala, Elías, "Científicos e ingenieros en la Nueva España. Don Diego García Conde en la Historia de la Cartografía Mexicana", Una visión científica y artística de la Ciudad de México. El plano de la capital virreinal (1793-1807) de Diego García Conde, México, Centro de Estudios de Historia de México Condumex, 2002: 17-42.

Fecha de recepción: 8 de noviembre de 2013.

Fecha de envío de las modificaciones: 13 de mayo de 2014.

Fecha de aceptación: 21 de mayo de 2014. 


\section{Diego García Conde, a Spanish soldier in the transition to Independent Mexico}

Diego Garcia Conde belonged to a long line of Spanish soldiers who rose to key military positions in the eighteenth century. The four Garcia Conde brothers reached the rank of Field Marshal; two of them performing their duties in Spain, while the others were destined to New Spain. Diego Garcia Conde particularly stood out throughout the time he spent serving both the Spanish colonial Government and the new Mexican independent State: he was Military Commander and Governor, the first Director of Engineers of the new nation, as well as Director of the Military Academy. As a volunteer engineer, he also undertook major scientific work, including drawing up a map of Mexico City.

Key words: Diego García Conde; military engineer; New Spain; Cartography. 